\title{
Successfully Teaching Ethics for Effective Learning
}

\author{
Ronald R. Sims, (Ronald.Sims@business.wm.edu ), College of William and Mary \\ Edward L. Felton, Jr., (Ed.Felton@business.wm.edu ), College of William and Mary
}

\begin{abstract}
This paper is concerned with identifying keys to successfully teach ethics. The keys are: addressing the relevance challenge; striving to achieve a balance between the active engagement of students with issues and a critical analysis of choices in to be made in real-life situations; attending to or managing the learning process to include learning styles and experiential learning; debriefing experientially-oriented learning activities; and institutionalizing outcomes of ethics education objectives. The paper discusses results of a study that attempted to answer the question "What is required to successfully deliver experientially-oriented ethics education
\end{abstract}

\section{Introduction}

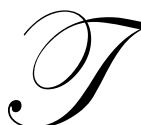

he academic study of ethics is at least 2,300 years old. Questions of right and wrong were discussed at length by both Plato and Aristotle during the classical period in Athens and have been treated by Western philosophers since then. In Oriental philosophy, such discussions first appeared even earlier. Ethics has been interwoven with every aspect of professional education since the first professional schools were established in the great river civilizations of China, Egypt, and Sumeria. These were schools of administration and not business administration. The point is nevertheless the same. For five millennia, professionals have defined their role and standing in society in part by their relationship to society, and that relationship entails ethical obligations.

Moral education was the primary goal of the first United States colleges, and "the central goal of the curriculum and even the entire college environment was to develop sensitivity to moral responsibilities, to teach ethical thought and action, and to develop students' character” (McNeel, 1994, 27). A whole-person education best describes higher education in the United States in its original form (McNeel, 1994). The colleges that were founded during the colonial period focused on building character to prepare students for leadership roles in civil and religious organizations (Boyer, 1990), and as far back as 1749, Benjamin Franklin linked education with morality and service (Fleckenstein, 1997). Boyer (1994) goes so far as to posit that "Higher education and the larger purposes of American society have been, from the beginning, inextricably intertwined” (p. A48).

One of the basic premises of this paper is that ethics can and should be taught (and learned) in institutions of higher education, even though it may be difficult in some situations to do so. This paper will first speak to the issue of whether or not higher educations should and can teach ethics before turning to a discussion of the importance of addressing the relevance challenge in teaching ethics. The focus then turns to the need to continuously strive to achieve a balance between the active engagement of students with issues and a critical analysis of choices in our teaching ethics efforts. Next the importance of attending to or managing the learning process in schools is highlighted as the section takes a look at the 
importance of learning styles and experiential learning along with some reasons why ethics teachers should not teach to student's learning styles. Some cautionary reflections on using debriefing in teaching ethics are then introduced. The need to institutionalize outcomes precedes the discussion of some findings gathered from a preliminary convenience study of the aspects of effective and ineffective ethics education. We then offer some suggestions on what is required to deliver ethics education based on interviews from a convenience study, discussions with colleagues and our own experiences with experiential learning theory in teaching ethics.

\section{Teaching Ethics: Should Institutions of Higher Education? Can Institutions of Higher Education?}

Should institutions of higher education teach ethics? Can institutions of higher education teach ethics? As you may suspect, this paper would not have been written if the answer to either question were "No." Additionally, it would be safe to surmise that financial and other resource commitments by colleges and universities and companies over the years along with more recent partnership between corporations and universities are clear indications that there are those who believe higher education institutions should and can teach ethics; that is, that the moral development of students can be enhanced through the education process.

While few doubt that ethics are learned, many are not convinced that ethics can be taught. Dissenters from both the business and academic communities have raised serious questions about whether ethics can or should be taught (Trevino and Nelson, 1999). For example, some question whether teaching ethics is possible, arguing that it is too late to start ethics education at the university or college because students come to the higher education institution with firmly set values and are not likely to change these values. More specifically, some critics argue that ethics courses cannot be effective since values are formed early in our lives and according to Miller and Miller (1976) "honesty" is not a course to be taught.” Felix Rohatyn, a noted New York investment banker, said that ethics cannot be taught past the age of 10. Lester Thurow, former dean of the Massachusetts Institute of Technology's Sloan School of Management, echoed this view when he stated that institutions of higher education can do little if students have not already learned ethics from families, clergy, previous schools, or employees (Trevino and Nelson, 1999).

There is some research that supports the view that ethics cannot be taught. For example, Martin (1981) found that two ethics courses offered by the Philosophy Department did not significantly impact the students' ability to correctly assess the ethics scenarios presented to them. Similarly, others failed to find any significant impact resulting from students enrolled in a business ethics course (Brinkmann and Sims, 2001; Trevino and Nelson, 1999; Stewart, et al., 1996; Piper et al., 1993).

Other recent research has found that ethics courses have a significant impact on students' ethical sensitivity and reasoning skills (Weber and Glyptis, 2000; Carlson and Burke, 1998) and that moral behavior can be developed from a thorough understanding of ethical concepts and dilemmas and reinforced by awareness of ethical issues (Alam, 1999; Sims and Sims, 1991). In a recent editorial, the Wall Street Journal announced that ethics courses are useless because ethics can't be taught. Although few people would turn to the Wall Street Journal as a learned expert on the teaching of ethics, the issue raised by the newspaper is a serious one: Can ethics be taught (Markula Center for Applied Ethics, 2004)?

McCabe et al. (1991) reported that psychology literature supports the argument that education is one of the most consistent and powerful correlates to the development of moral judgment in individuals. Moreover, Nonis and Swift (2001) suggested that an individual's values affect his or her ethical decision making. And, because values can be taught, ethical practices can be influenced. Finally, Gioia (2002) 
indicated that educators influence students in their learning about business. Therefore, higher education faculty members should be able to influence students in their learning about ethics as well.

The issue of whether or not ethics can be taught is an old one. Almost 2500 years ago, the philosopher Socrates debated the question with his fellow Athenians. Socrates' position was clear: Ethics consists of knowing what we ought to do, and such knowledge can be taught. Most psychologists today would agree with Socrates. In an overview of contemporary research in the field of moral development, psychologist James Rest (1986) summarized the major findings as follows:

- Dramatic changes occur in young adults in their 20s and 30s in terms of the basic problemsolving strategies they use to deal with ethical issues.

- These changes are linked to fundamental changes in how a person perceives society and his or her role in society.

- The extent to which change occurs is associated with the number of years of formal education (college or professional school).

- Deliberate educational attempts (formal curriculum) to influence awareness of moral problems and to influence the reasoning or judgment process have been demonstrated to be effective.

- Studies indicate that a person's behavior is influenced by his or her moral perception and moral judgments.

Much of the research that Rest alludes to was carried out by the late Harvard psychologist, Lawrence Kohlberg. Kohlberg (1981) was one of the first people to look seriously at whether a person's ability to deal with ethical issues can develop in later life and whether education can affect that development. Kohlberg (1981) found that a person's ability to deal with moral issues is not formed all at once. Just as there are stages of growth in physical development, the ability to think morally also develops in stages (preconventional, conventional and post conventional).

Many factors can stimulate a person's growth through the three levels of moral development. One of the most crucial factors, Kohlberg found, is education. Kohlberg discovered that when his subjects took courses in ethics and these courses challenged them to look at issues from a universal point of view they tended to move upward through the levels. This finding, as Rest points out, has been repeatedly supported by other researchers.

Can ethics be taught? If you look at the hard evidence psychologists have amassed, the answer is yes. If you read the Wall Street Journal, you wouldn't have thought so.

Despite these recent findings it is intriguing that many are still not convinced that ethics can be taught. Perhaps this tension, encountered when teaching ethics is incorporated into the college and university curriculum, can be reframed to open the way for constructive discussion if the question is rephrased as: "If ethics can be taught to students, then how can higher education teachers successfully teach ethics for effective learning?”

\section{The Relevancy Challenge in Teaching Business Ethics}

Students and faculty alike complain that textbook and classroom materials are too theoretical and have little or no application in the so-called "real world." This is often especially the case with ethics. Thus, there should be no surprise that a major criticism of efforts to teach ethics over the years has been the lack of relevancy for students. Zoellers and Fort (1996) have noted that teaching ethics is different from teaching other courses in a business school or college or university). Additionally, some scholars have argued that one has to contend with issues such as ambiguity, credibility, relevance and 
effectiveness (McDonald and Donleavy, 1995). The criticism of irrelevance may be intensified during the exposition, for example, of classical moral theory such as Kant’s categorical imperative.

Higher education' faculty have a responsibility to ensure that students learn how to appreciate and fully engage topics like ethics. Consider the following experience.

A few years ago we invited a very successful CEO and principal stockholder of a chemical company to speak to our accounting students. Our speaker was very successful financially and very comfortable with making economic trade-offs between fines for chemical pollution of the environment and business profitability. Also, speaking as an international businessman, he expressed his unhappiness that U.S. legislation imposed criminal sanctions for certain "corrupt" practices that other countries treated as civil problems subject to fines. He argued before the students that on a level playing field the U.S. should not subject him to exposure for "jail time" when other countries would allow him to pay for his premeditated transgressions with fines. Our speaker also identified new international opportunities by naming countries more welcoming to chemical production that would offer greater profit potential because of lax or unenforced environmental restrictions. He ended his remarks by welcoming inquires from interested students. He was, as he said, always on the watch for a few "good accounting students" to add to his staff.

Our guest was controversial. Some students were upset that such a politically incorrect speaker could have slipped through our sensors. How could we expose students to such a pernicious influence? Other students found themselves more interested in the formula for economic success. It was clear that the students were engaged. How was our speaker defining a "good business student?" The theoretical world of ethics had been translated into a practical question: Do I want to leave a resume with the placement office to get on the interview schedule with this company? To make the problem more interesting, we can add that our speaker was a member of the "advisory board" of a business school located in his home city.

The challenge of relevance is to achieve a direct connection between personal choices and real problems and issues. The teaching of ethics should provide both a theoretical and experiential framework that students can apply in evaluating a situation and choosing between conflicting moral demands. In such a program and/or course, the analysis relies on human reason to raise important questions of morality and to provide logically defensible responses.

In 1978, Edmund Pellegrino, then a university president, wrote a classic paper entitled 'Ethics and the Moral Center of the Medieval Enterprise', published in the Bulletin of the New York Academy of Medievalism. In it, Pellegrino stated:

Ethics comes into existence, properly speaking, when morality itself becomes problematic, when the validity of beliefs about what is right and good comes into question, or when a conflict between opposing moral systems or obligations must be resolved. Morality takes its values and beliefs for granted as presuppositions that apply to all men.

Pellegrino further wrote:

Ethics emerged as a formal discipline when the Sophists and Socrates first began to question Greek presumptions about the right and the good in political and social life. Among them, morality for the first time became explicitly problematic and the history of ethics since then has been an attempt to examine the presuppositions about what is right and good and what should be normative for human actions. 
In essence, by employing the theories of moral philosophy in conjunction with a need to inquire about what is right and wrong, students will be able to examine their own value systems as well as those operative in the real-world of work environment of the private, public and not-for-profit sectors. If institutions of higher education in general are intended to be liberating experiences, designed to develop a student's skills of inquiry, understanding, and expression, then the ethical dimension should serve as a benchmark for a student's education as well as a foundation upon which to build a successful career.

For students to derive the most from ethics education, faculty must insure that their efforts reflect those issues that students need to realistically understand. That is, ethics education must be geared to the more immediate and personal issues that students are likely to encounter throughout their careers. To accomplish this goal, higher education teachers must continue to avoid the tendency to use pedagogical approaches that reflect a strong bent towards dilemmas that have no direct relevance to the roles that students will occupy in organizations. What is needed is an emphasis on the real-life situations or actual experiences of practicing employees, administrators and managers (Maclagan and Snell, 1992; Sims and Sims, 1991) where students must be able to apply moral reasoning and develop skill in ethical reasoning (Brinkmann, and Sims, 2001; Trevino and McCabe, 1994).

Real-life situations reflect the type of challenges students are likely to face and help them bridge the gap between theory and application as case discussions become more relevant and focused on real life situations that reflect the types of situations students are likely to face in organizations. When brief anecdotes are included in textbooks for student discussion, the anecdotes may lack the context necessary for comprehending the ethical dimensions of the situation. These contextual factors include that human beings themselves play highly differentiated roles and have different norms to guide them in different social contexts (Trevino and McCabe, 1994), their organizational culture, and the culture of the society which supports their institutions (Furman, 1990). In addition, students must learn to recognize ethical dilemmas when they are embedded in the complexity of real-life situations. Finally, multiple, and often conflicting, claims are placed on new employees, an issue which must be addressed when teaching ethics, particularly to undergraduates (Furman, 1990). Thus, the classroom experience needs to involve students in discussion that addresses both defining and resolving ethical dilemmas.

In summary, the challenge of relevancy can be expressed in terms of the following operational objectives:

- Create and foster awareness of the ethical components of organizations/business;

- Legitimize the consideration of ethical components as an integral part of decision-making;

- Provide a conceptual framework for analyzing the ethical components of decision-making and making choices; and

- Help students apply ethical analysis to the very real and practical, day-to-day activities.

To achieve the objectives of teaching ethics the following steps should be taken:

1. Trained staff in multidisciplinary areas should be employed who can relate their discipline(s) with the overall organization/decision-making.

2. Creation of a organization or real-world-like environment in the class.

3. Organization of workshops to develop different skills and competencies.

4. Coordination of different disciplines through case studies.

5. Invitation of consultants from outside to provide the broader view of the various organizational sectors.

6. Potential employers should be invited to contribute in designing curricula.

7. Analysis of administrative or management practices.

8. Proper coordination of different disciplines. 
9. Development of a fictional organization.

10. Development of courses on ethics and society.

11. Role playing.

12. Development of courses relating to social implications of individual and organizational decisionmaking.

13. Rounded education at lower level and specialization at the higher level.

14. Student should be provided with work place experience.

\section{Balancing Philosophical and Practical Extremes}

Successfully teaching ethics requires that ethics teachers continuously strive to achieve a balance between the active engagement of students with issues and a critical analysis of choices. In our view, this balancing act is usually the result of faculty having to wrestle with two traditional and conflicting alternatives to teaching ethics. The first method stresses background knowledge and analytical procedures clearly needed for rigorous moral evaluation. The second method uses cases extensively and focuses much more on the functional and strategic problems of organizations.

Many of us are confronted with the situation where it is hard to get students in the classroom to apply specific ethical principles to precise organization problems. Students often propose unworkable alternatives to avoid the moral choice and question facts to delay the inevitable decision. And, in numerous situations instead of arguing from the ethical principles the course is attempting to convey they argue from the personal opinions they have held for years. Two writers recently described this exact problem in their own classes (Fort and Zollers, 1999):

Even an ethics course that requires mastery of a good deal of normative theory is likely to depend upon a high degree of class participation. There thus develops a paradox of, on the one hand, encouraging students to be involved actively in discussion and, on the other hand, avoiding merely superficial sharing of "warm" feelings that avoids critical analysis and dialogue. How does a professor strike a balance whereby students are passionately engaged yet critically analytical, while exploring unfamiliar and challenging material? (p. 274).

One writer has proposed a format for increasing the likely success of achieving the balance between active engagement of students with the issues and a critical analysis of the choices (Hosmer, 2000). Briefly, the standardized format handed out to students each time a major case is assigned and the students are required to fill in the blanks thoughtfully, and hand back the forms for grading. There are 20 questions to be answered and the ethics teacher assigns a maximum of five points for each question. According to Hosmer "consequently grading on the familiar scale of 0 to 100 is straightforward and simple." Each question (section) that requires a response comes with a brief description of the issue to be addressed or the principle to be applied. To date, Hosmer notes that the format works remarkably well and has resulted in dramatic improvements in class discussions. Further, Hosmer believes that students are working up the hoped for scale (Rest and Narváez, 1994) of moral sensitivity, moral judgment, moral motivation and finally, moral character. One of the authors has used a modified version of this standardized format to date and would highly recommend it as an excellent way of successfully balancing the philosophical and practical approach to teaching ethics. Those interested in finding out more about this approach should see Hosmer (2000). A copy of the standardized format for case analysis of moral problems can be found in Appendix I of the Hosmer's article.

\section{Attend to and Manage the Learning Process}


Higher education teachers responsible for teaching ethics like others are aware of the ongoing changes in themselves and students during this period of great change and experimentation in colleges and universities. As they facilitate learning, growth and development in students during these times of change, faculty responsible for teaching ethics struggle to improve themselves and to become more effective classroom leaders, planners, presenters and facilitators. Faculty must not only respond to the demands created by very complex organizational, professional and technological environments but also reexamine their choice of pedagogy and their assumptions about the learning process. Rather than using only the teaching style with which they may be most comfortable and familiar, those responsible for teaching ethics must learn to use new techniques and approaches to respond to a variety of educational goals and a variety of student approaches to the learning process.

David Kolb (1984) and others committed to experiential learning say that adults will learn "no matter what." Learning is as natural as rest or play. With or without books, visual aids, inspiring teachers, or classrooms, adults will manage to learn. Higher education teachers can, however, make a difference in what students learn and in how well they learn it. If students know why they are learning about ethics, and if the reason fits their needs as they perceive them (the "so what?"), they will learn quickly and deeply. In addition, the extent to which institutions of higher education faculty and administrators take time to manage the learning process through development of curricula, student's learning will be enhanced.

To conduct the educational process in colleges and universities in a manner that attends to the individual learning styles of students and fosters student development requires management of those aspects of the educational system that influence the learning process. Such a management system must be soundly built on a valid model of the learning process. There has been a great burgeoning of approaches or techniques for teaching ethics designed to assist the learning process in recent years: computer-aided instruction, experienced-based learning materials, programmed instruction, simulations and games, multimedia curricula, service learning projects, and so on. Although these techniques tend to be highly sophisticated and creative applications we must constantly ask ourselves if they are enhancing student learning. The weakness of nearly all these techniques is the failure to recognize and explicitly provide for the differences in learning styles that are characteristic of both individuals and subject matters like ethics.

Even though many of these teaching ethics innovations have been developed in the name of individualized education and self-directed learning, we still believe there has been little attempt to specify along which dimensions individualization is to take place. For example, although computer-aided instruction and programmed learning provide alternative routes or branches for the individual student, these branches tend to be based primarily on various elaborations of the subject matter being taught (i.e., a wrong answer puts the student on a branch giving him or her more information about the question). Little has been done to provide the individual student with branches that provide alternative learning methods (such as those that differ from the faculty members preferred style or method) based on the student's learning style. In addition, there has been little research to assess how the effectiveness of various approaches to teaching ethics is contingent on either individual student learning styles or the type of subject matter being taught. 


\section{The Case for Not Teaching to Student's Learning Styles in Ethics Education}

We believe we would be remiss in our responsibilities in offering our views on the value of using learning styles to enhance learning and the teaching of ethics if we did not note that on the face of it, a simple proposition seems to hold the key to effectiveness. If ethics teachers wish to connect with as many students as possible, all they need to do is to find out about the learning styles these students exhibit and then adjust their teaching exercises and materials to the spread of styles revealed. However, it is important for the ethics teacher to keep in mind that in determining how someone is going to learn something a number of variables other than an individual's preferred learning style are of equal or greater importance. Chief among these are the nature of the learning task, the student's level of learning readiness, the student's previous experience and knowledge in this area, the student's and the teacher's personalities, the personalities of other learners, the political ethos of the school and the broader educational institution, and the dominant values and traditions of the culture of which the student is a member. The idea of teaching to easily identifiable learning styles, while superficially simple, is in reality highly complex and this complexity must be taken into consideration by the teacher in any ethics teaching effort.

In fact, rather than those responsible for teaching ethics always adjusting their practice to account for students' preferred learning styles, a good educational case can be made for doing precisely the opposite. In other words, instead of affirming the habitual, comfortable ways our students go about their learning - some of which may involve deeply etched, self-defeating habits - ethics teachers should think about introducing them to alternative modes of learning.

We have found that the real value in Kolb's experiential learning model is its emphasis on the importance of developing student's ability to develop learning strengths in each of the four learning modes and not just to teach to a student's preferred learning style. The model recognizes that most learning and life episodes require a variety of learning responses thus it is sometimes important to teach against students' preferred learning styles. If the ethics teacher has the students' best interests at heart, they may well decide that the last thing they need is to be confirmed in a comfortable, but narrowly focused learning style. It is far better to introduce students to a diversity of ways of planning and conducting learning.

The principle of diversity should be engraved on every ethics teacher's heart. In evaluating the performance of a ethics teacher's (or any teacher for that matter) or in judging the merit of an educational approach, one of the first things we look for is diversity. Are teachers using a range of teaching approaches? Do they use a variety of teaching materials? Do they alternate opportunities for individual study with group collaboration? Do they mix lectures, cases, discussions, experiential learning pedagogies and techniques? Do they incorporate various philosophical and other ethical theories in their teaching efforts? Do they allow for periods of reflective analysis?

Keeping diversity at the forefront serves two important functions. On the one hand, ethics teachers stand a good chance of connecting to the preferred learning style of most of their students at some point in their teaching. We have found that at this point, students will feel comfortable with, and affirmed in, their learning. On the other hand, the ethics teachers probably also introduce most students in their classes to learning modes and orientations that are new to them. Students' repertoire of learning styles will thus be enlarged and they will be more likely to flourish in a greater range of settings outside the academy than would otherwise be the case. 


\section{Reflections on Debriefing}

Several cautionary reflections are worth highlighting for those interested in using experiential learning exercises and debriefing in their teaching ethics efforts. First, you must recognize that not all students will respond favorably to ethics in general and experiential learning exercises and debriefing in particular. Second, many students are not prepared to take on the active role that is being asked of them as learners nor will they see this as an opportunity for them to develop new and different relationships with faculty members responsible for the course and their fellow classmates. That is, motivation to be involved varies by student. Some exhibit great enthusiasm to experiment with novel situations, while others are reluctant to do so. Third, don't be surprised by differences between students in one class to the next in their willingness to participate in both the experiential learning exercises and debriefing which require that students discuss their attitudes, values, feelings and behaviors. We have experienced first hand the difference between students in two sections of a course on Business and Society. One group of students was energetic and open to trying new things and actively participated in the experiential learning activities and the subsequent debriefings throughout the course. Students in the other course appeared to be more resistant to the whole topic of ethics, experiential learning exercises, and debriefing. On a similar note, the number of international students in a course can also have a profound impact on the dynamics of the course. Some of them, in our experience are not comfortable with the whole idea of debriefing. It is nor unusual for some international students who may be notorious for proficiency at exams and a deferential attitude towards professors to view debriefing as strange and even more frightening than students from the United States.

In our more than 20 years of teaching each we have come to believe that skepticism towards and dislike of ethics, experiential learning exercises, and debriefing is a common denominator among many faculty. Although a good debriefing may look as if it is natural and spontaneous, it does require a different role for faculty who may not be comfortable with a more active student or learning process. Altering ones teaching approach or style like relying on what may be a new pedagogical approach (i.e., experiential learning exercises) is a cost, at best an investment of energy and time, with expected return as a key variable. Additionally, using debriefing in teaching ethics can be emotionally more challenging and more risky for faculty than teaching other subjects. Faculty who are interested in using such an approach must be prepared for challenges and risks which may relate to their self-conception, to the communication climate in the classroom and to their role authority as a function of both.

While there is no clear timeframe for becoming proficient with the debriefing approach in teaching ethics, in our experience, the greatest obstacle is the ethics teacher's fear of personal dissonance and of losing control in the classroom. If being in control at all times and keeping a distance from students is one's preferred style - the ideas offered in this paper will not be of much benefit. Finally, perhaps the best advice we can offer to our colleagues is to keep two things in mind-"You must know your audience" and "Prepare, be patient and be flexible." Failure to follow this advice will result in missed opportunities to help students see the value of debriefing and thus, maximizing their learning about ethics.

\section{Institutionalizing Outcomes Assessment}

Institutions of higher education should make every effort to institutionalize outcomes assessment, and those responsible for ethics education can take the lead in this area. We can take the lead in finding answers to questions like: 
1. What makes for good assessments? Good assessments begin with clear educational purposes, expectations and learning objectives. We always find it helpful to see if our teaching ethics goals or objectives pass the SMART Model: are they specific, measurable, attainable, results-oriented, and timely.

2. What is good assessment information? The goodness of assessments is determined by their validity and reliability. Validity, the most important characteristic of assessments, is concerned with the collection of information that is most appropriate for making the desired decision. Reliability is concerned with the consistency or typicality of the assessment information collected. Assessment begins when we establish learning objectives for a school, program, course or activity.

3. Is there an important difference between good teaching and effective teaching? What is good teaching? What is effective teaching? Good teaching refers to the process of instruction, while effective teaching refers to the outcomes of instruction. Good teaching deals with how we organize and present our instructional activities in order to engage students in the learning process. Effective teaching goes one step beyond good teaching to focus upon what students have actually learned from instruction. Clearly, there is a relationship between good and effective teaching; the better the teaching, the more likely that it will be effective.

Those responsible for teaching ethics can also benefit from focusing on these questions as they think about how to measure and evaluate their effectiveness in teaching ethics:

- What is it I am teaching?

- What knowledge and abilities must students achieve?

- How do I know when they've achieved them?

- How good is good enough?

- What, ideally, would I/we like students to learn and be able to do?

- Am I teaching what I think I am teaching?

- Am I helping people learn?

\section{The Interviews}

In order to gain some additional insight into factors contributing to effective ethics education and to validate the challenges it faces as advanced in this paper we conducted a convenience study. Twentytwo individuals participated in one-on-one interviews. These individuals were between 30 and 55 years of age and had from two to 16 years of experience as ethics educators. Each person described a peak and a nadir experience of ethics education by responding to the following protocol based on the Kolb's experiential learning cycle. According to Kolb’s experiential learning theory (ELT), learning proceeds as a cycle and results from the integration of four learning modes: concrete experience, reflective observation, abstract conceptualization, and active experimentation. More specifically, students must be able to fully and openly engage in new experiences; reflect on, observe, and consider these experiences from various perspectives; create concepts that assimilate these experiences into sound theories; and appropriately apply these theories to their life situations. This cycle of learning is at the center of Kolb's experiential learning model. Thus, the underlying premise of Kolb's cycle or learning sequence is that learners learn best when they are active, take responsibility for their own learning, and can relate and apply it to their own context.

The question stated in our convenience study, "Think about a time when you were either a teacher in an ethics education session that was particularly (ineffective or effective) in terms of your learning and the learning of others.” 
- Concrete Experience: Tell me about the experience-what happened? What were your thoughts, feelings, and perceptions at the time of the experience?

- Reflective Observation: Since the time of the experience, what have been your key reflectionshow do you make sense of the experience now?

- Abstract Conceptualization: What are your conclusions as a result of the reflection and efforts to make sense of the experience?

- Active Experimentation: What rules of thumb and guidelines would you include in any future ethics education designs?

Data were analyzed for recurring comments or themes that are listed in Table 1. Findings are presented without interpretation. Factors that contribute to effectiveness in teaching ethics are storytelling, trust and safety, dialogue, gaining personal insight, broadly defining ethics, teaching more than cognition, ethics education efforts lasting more than one day, clear expectations and goals, and a diverse group of students and teachers. Characteristics of ineffectiveness are negative perceptions of faculty, lack of closure of emotional issues, lack of trust, ethical theories or models as sole foci of the course, feeling unable to be heard, feeling personally attacked or blamed, and the ethics education effort lasting one day or less.

Table 1

Aspects of Effective and Ineffective Ethics Education

\begin{tabular}{|l|l|}
\hline Effective Experiences & Ineffective Experiences \\
\hline storytelling & negative perceptions of faculty \\
\hline trust and safety & lack of closure of emotional issues \\
\hline dialogue & lack of trust \\
\hline gaining personal insight & $\begin{array}{l}\text { ethical theories or models as sole foci of the } \\
\text { course }\end{array}$ \\
\hline broadly defining ethics & feeling unheard \\
\hline teaching more than cognition & feeling personally attacked or blamed \\
\hline $\begin{array}{l}\text { ethics education efforts lasting more than one } \\
\text { day }\end{array}$ & $\begin{array}{l}\text { insufficient class time-- effort lasting one day } \\
\text { or less }\end{array}$ \\
\hline clear expectations and goals & a diverse group of students and teachers \\
\hline
\end{tabular}

Females and males were evenly split in identifying storytelling and dialogue as useful learning tools. The two activities are related. Storytelling it seems, impacts students in ways that arouse curiosity and a desire to engage in dialogue and often leads to personal insight. Females spoke about trust as a component of effective ethics education while males associated feeling safe (from attack and blame) with a satisfying experience. Broadly defining ethics positively impacts the experience of males more than females. Expanding the context of ethics creates the opportunity for students to personally relate to others and (work) ethical experiences and positions them for more receptivity to the more controversial aspects of ethics such as racism, sexism, etc. This opinion is expressed across ethnic and gender boundaries of persons interviewed. A couple of individuals suggested gradual movement toward the discussion of "hot button" or controversial ethical issues or dilemmas. Ethics is less satisfying for many of the individuals in this study when limited to a focus only on either knowledge acquisition or practice.

Ethics educators in this study emphasized that teaching is more important than cognition in a class on ethics. Efficacy in ethics education is unlike competency or skill building where you can be very objective and still do a good job. It touches everyone's feelings. Effectiveness also necessitates more 
time. Those interviewed felt that two to three day is the minimum time for teaching ethics. Less time often leaves students with unresolved issues. Lack of closure of emotional issues is an aspect of ineffective ethics experiences. One teacher provides individual discussions with students taking classes on ethics. This highlights the importance of debriefing.

Experiences of ethics education are more positive for those interviewed when ground rules and goals are clarified, particularly when this occurs at the beginning of the semester or quarter. One educator is committed to what he refers to as community building where objectives, ground rules, and roles are explicit and total group as well as subgroup is seen as important. Identifying personal goals for some individuals is just as critical as goal setting for the class in general.

A team or interdisciplinary approach to teaching was preferred by all of the individuals. Having a diverse team of faculty models the complexity and inability to compartmentalize ethics. A multicultural class of students provides richness of discussion and diminishes feelings of isolation and loneliness. Teacher skill was more a concern for males than females. Negative perception of faculty was a key aspect of ineffective ethics education experience. Elements of this theme are perception of faculty as coercive (my way or the highway), lacking in process skills, unclear about their own inability to listen and be open to new ways of viewing or interpreting ethical or philosophical theories and responses to ethical dilemmas.

Themes from the interviews confirm the challenges confronting ethics education as briefly highlighted in this paper. Interviewees underscore the need for dialogue, psychological safety, and student or learner directed education. In singling out a requirement for more than cognition, the usefulness of a more comprehensive method of teaching is also highlighted.

\section{Experiential Learning Theory and Learning Styles in Ethics Education}

If experiential learning theory offers ethics education a framework that integrates personal experience and practical application with perceptive appreciation and understanding of concepts, what then is required to deliver ethics education? We offer some suggestions based on interviews, discussions with colleagues, and our own experiences with experiential learning theory in ethics teaching.

\section{Build Ethics across the Curriculum}

Ethics cannot be learned in one course; it must be located in courses across the curriculum. This has increasingly become an important addition to our pedagogical arsenal because it has made us more fully aware that skills build up over time and that practicing them only once or twice does not get us very far. Like writing, what absurdity to think that one can teach ethics in a single course! We know that the principle of continued exposure and practice should not need much advocacy in regard to teaching ethics and learning to apply ethical principles.

\section{Position Ethics Education as a Holistic Process}

It is useful to inform students that an ethics course based on experiential learning might belie some of their assumptions about the teaching process and their role in it. Unlike traditional approaches to learning where teachers are experts and students are passive recipients of the information that is disseminated, here responsibility for learning will be shared by teacher and student. In that a course on ethics is not merely a new content area, it summons all of who students are - their intelligence, their perception, their practicality, and most importantly their emotions. The approach to learning must be 
guided by a holistic framework and include a range of activities including experiential exercises, discussions, readings, and role-plays.

\section{Clarify the Role of the Ethics Teacher}

Generally, and particularly in ethics education, experiential learning theory requires a different role for the teacher from the one typically seen. That role needs to be clarified. The teacher's role is less one of purveyor of knowledge and more one of managing a classroom as a learning organization. We have found that at any given time the ethics teacher could be a role model and colleague, who supports awareness of human experience in the moment; a process consultant who keeps on track an engaging discussion of ethics, ethical behavior, ethical principles, and so on; an interpreter of knowledge, who does a brief lecture on ethical theories and models; or a coach, who supports the planning of transfer of learnings.

\section{Clarify the Role of the Student}

Experiential learning is individualized and self-directed learning. Students who are unaccustomed to this approach may have difficulty with assuming responsibility for achieving their learning objectives. Ethics teachers will need to work with students so that they see value in their own experiences and applying new knowledge, skills, and attitudes to their life situations.

\section{Assess Learning Styles of Students and Faculty}

Learning style immediately creates an alternative view of differences in students that faculty must take into consideration. Any of the many learning style inventories available (see for example, Kolb's (1999) LSI III for an example of a learning style inventory) gives individuals data about which aspects of the learning process they prefer. It also has implications for classroom activities, faculty role, feedback, student engagement in material, and faculty-to-student dynamics. The LSI III, when administered in class using the LSI grid, provides data about the learning community that is immediately available to everyone. It is intriguing to watch students act out their learning style during the discussions. Some struggle with feelings they have, others question the pragmatics of the model or challenge the theory behind it, and others just watch and take it all in.

\section{Establish a Psychological Contract}

The importance of psychological safety and feelings of trust in ethics education is emphasized in the literature (see for example, Sims, 2002) and interviews conducted for this paper. Learning environments and dialogue are constructive mechanisms toward creating the ideal climate of learning. The act of negotiating a psychological contract is good for establishing trust and should take place during the first class session. The psychological contract involves the ethics teacher's expectations of students and students' contributions to meet those expectations. It also deals with students' expectations of a course, for example, or ethics teacher and the contributions to meet those expectations. The pinch model (Sherwood and Glidewell, 1971) captures the dynamic nature of psychological contracts and suggests strategies for renegotiation when "pinches" or disruption of shared expectations occur. The psychological contract in ethics education efforts should be designed to be a real agreement among members of the learning community-students and teachers alike- that guide their behavior for the entire ethics education effort. 


\section{Identify Guidelines of Behavior}

Guidelines complement the contracting process and like the psychological contract should be identified on the first day of class. Identifying guidelines, of course, is a joint activity between students and teachers. Guidelines to consider include honoring confidentiality, affording mutual respect, speaking from personal experience, and engaging in interpersonal conversation. Confidentiality creates a dilemma for students whose learning is supported by discussion outside the classroom, which we encourage and sometimes request. We ask students to refrain from attaching names to opinions or experiences shared by their classmates. Simply put, mutual respect is behavior consistent with the Golden Rule. It is the act of acknowledging that we all hold perspectives of the world that even when they differ are valid for each of us.

\section{Encourage Dialogue}

Design activities that allow for discussion and processing of experience. Dialogue itself begins with speaking from personal experience and owning experience through the use of first person language "I," "my," "me," "mine.” First person language is more engaging in dialogue than the more distant and abstract third person. It lends to "straight talk" - use of clean, clear, direct communication that fosters connections between two parties of equal status. Good conversation requires both speaking and listening and in this regard is not monological. Gestalt principles emphasize calling the other by name as a first step toward good interpersonal contact. Calling someone by name serves to plant a seed for relationship building. Another Gestalt approach to good conversation is to find ways to engage not two or a few but all students in total classroom discussion. Good conversation leads to good moral conversation, and both are key to conversational learning.

\section{Foster Challenge}

The insight that students remember as transformative comes from those learning episodes in which some element of challenge was involved. Challenge has a powerful effect on the teaching of ethics. One of the most laudable characteristics of ethics teachers is their readiness to affirm and encourage students to learn. In our experience, such affirmation is crucial to strengthening a student's sense of self-regard.

Taken to its extreme, however, affirming students can lead to an educational cul-de-sac in which students feel good about themselves but are never prompted to explore alternatives perspectives, to venture into new skill areas, or to scrutinize critically those habitual assumptions underlying their ethical thoughts and actions. To live in a cul-de-sac is quietly comfortable, but it may be self-defeating. But students are sometimes so enclosed within their narrow frames of reference that they are the last to recognize that these may be self-defeating and harmful. Thus, often the most important thing an ethics teacher can do for his or her students is to challenge them with alternative perspectives, new activities, and critical reflection.

\section{Utilize a Variety of Group Structures}

It is important to mix groups during various activities based on the difference represented in the class (e.g., race, gender, learning style, organization type). It is also advisable to use a variety of structures - pairs, trios, small groups, and total community. We find especially useful the small group structure referred to as "learning teams" that meet during the formal structure of the class as well as outside of class. Time constraints, class size and other related factors do not always allow for the 
appropriate and thorough processing/debriefing of student experience within the classroom setting. Learning teams allow for continued processing/debriefing of experience and serve as support groups for identifying goals and for monitoring toward goal achievement. They enrich the learning process, provide a stable reference group, and facilitate trust that spills over into the classroom.

\section{Use Personal Application Assignments}

Readings, essays, term papers, thought pieces (a written stream of consciousness in reaction to readings or experiences), and group projects are mechanisms for teaching and learning about ethics and evaluation in ethics education. We like the Personal Application Assignment (PAA) that is used for evaluation of student progress by the student and teacher. The PAA is a paper that corresponds to the experiential learning model, since it is designed to indicate:

- A real situation (concrete experience)

- Understanding of the situation (reflective observation)

- Use of models and concepts to frame understanding of the situation (abstract conceptualization)

- Behavioral plans for similar situations in the future (active experimentation)

- Integration of the four preceding perspectives (synthesis)

The PAA is typically used in our ethics education efforts several times during the course of a semester and is similar to the interview guide of open-ended questions that students respond to as a way of monitoring their development over the course of the class. Used in this manner, it has been our experience that the PAA contributes to equalization of power between learner and teacher.

\section{Increasing the Number of Faculty Teaching Ethics}

Higher education institutions must also redouble their efforts to increase the number of experienced faculty teaching ethics. This means that there must be greater training opportunities for faculty interested in teaching ethics. There have been strides made in increasing the number of faculty teaching ethics and overall coverage of ethics in many college and university programs has increased over the past two decades. Faculty development and increased recruitment of faculty to teach ethics should receive increased attention by higher education institutions and accrediting organizations and other professional associations. Each of them should offer assistance through more workshops and conferences. This development must go beyond convening panels and include both financial and other investments. Colleges and universities can begin by asking themselves "Whether or not they support training and faculty development efforts to improve ethics education? If the answer isn't "yes” then higher education institutions can begin by identifying a strategy for rectifying the situation. Verbal encouragement alone is not enough if we are to increase the number of experienced faculty interested and actually teaching ethics.

\section{Conclusion}

The efficacy of ethics education rests on the degree to which all participants are able to own who they are as individuals, as group members, as citizens of a global community, and as learners, seeking knowledge and appreciation of self and other. Experiential learning is a theory of life and learning that celebrates human potential. As a paradigm of ethics, it appropriately prepares students as learners for life in an ever-changing society.

Perhaps the most important point that we can make in concluding this paper is to emphasize that we must deepen our knowledge of students considerably. Some faculty think they know students well 
enough already. But their views are shaped primarily by the appearances, or masks, that students put on in the classroom. We need to acknowledge not only how students learn, but their motivations and aspirations, the conditions that inhibit their learning or make it impossible like a classroom climate not conducive to learning and sharing in our ethics education efforts.

Higher education faculty today are overloaded, and their work stretches greatly beyond the canonical 40 hours. However, they must take the time to reorder or change the priorities. If they do not change them, then they should honestly say that making it possible for students to learn ethics and to keep on learning in general is not on the top of their agendas.

We must begin to look at our academic disciplines and ethics in fresh ways. How do our different fields look at ethics? How do our disciplines and ethics look from the point of view of students? Equally important, we want to build a framework upon which ethics can be taught, and we cannot leave it to the specialists alone, good as they may be. We the teachers, as those responsible for teaching ethics, need to articulate what we do. If more professors seriously consider the question of how students learn and the importance of teaching ethics, we will all help build an effective environment for teaching and learning ethics, and the rewards-for us and our students-will be exhilarating with fewer individuals committing ethical missteps like those highlighted in the recent wave of corporate scandals.

\section{References}

Alam. K.F. (1999). Ethics and accounting education, Teaching Business Ethics 2: 261-272.

Boyer, E.L. (1990). Scholarship reconsidered. Princeton, NJ: The Carnegie Foundation for the Advancement of Teaching.

Brinkmann, J., \& Sims, R.R. (2001). Stakeholder-sensitive business ethics teaching, Teaching Business Ethics 5: 171-193.

Carlson, P.J., \& Burke, F. (1998). Lessons learned from ethics in the classroom exploring student growth in flexibility, complexity and comprehension, Journal of Business Ethics 17: 1179-1187.

Fleckenstein, M.P. (1997). Service learning in business ethics, Journal of Business Ethics, 16(12/13): 1347-1351.

Fort, T.L., \& Zollers, F.E. (1999). Teaching business ethics: Theory and practice, Teaching Business Ethics 2: 273-290.

Furman, F.K. (1990). Teaching business ethics: Questioning the assumptions, seeking new directions, Journal of Business Ethics 9: 31-38.

Gilbert, J.T. (1992). Teaching business ethics: What, why, who, where, and when, Journal of Education for Business 68(1): 5-8.

Gioia, D.A. (2002). Business education's role in the crisis of corporate confidence, Academy of Management Executive 16(3): 142-145.

Hill, A., \& Stewart, I.C. 1999. Character education in business schools: Pedagogical strategies, 
Teaching Business Ethics 3: 179-193.

Hosmer, L.T. (2000). Standard format for the cane analysis of moral problems, Teaching Business Ethics 2: $169-180$.

Kolb, D. A. (1999). Learning style inventory-version 3: Technical specifications. TRG Hay/McBer, Training Resources Group. 116 Huntington Avenue, Boston, MA 02116,

Kolb, D.A. (1984). Experiential learning: Experience as the source of learning and development. Englewood Cliffs, NJ: Prentice Hall.

Kohlberg, L. (1981). The philosophy of moral development: Moral stages and the ideas of justice. San Francisco: Harper \& Row Publishers.

McCabe, D.L., Dukerich, J.M., \& Dutton, J.E. (1991). Context, values and moral dilemmas: Comparing the choices of business and law school students. Journal of Business Ethics, 10: 951960.

McDonald, G.M. \& Donleavy, G.D. (1995). Objections to the teaching of business ethics, Journal of Business Ethics 10: 829-835.

McNeel, S.P. (1994). College teaching and student moral development. In J.R. Rest \& D. Narváez (Eds.), Moral development in the professions: Psychology and applied ethics (pp. 2749). Hillsdale, NJ: Lawrence Erlbaum Associates, Publishers.

Maglagan, P., \& Snell, R. (1992). Some implications for management development research into managers’ moral dilemmas, British Journal of Management 3: 157-168.

Markula Center for Applied Ethics. (2004). Can ethics be taught? Retrieved 3/04/2004 at: http://www.scu.edu/ethics/practicing/decision/canethicsbetaught.html

Martin, T.R. (1981-1982). Do courses in ethics improve the ethical judgment of students? Business and Society 20(2) and 21(1): 17-26.

Miller, M.S., \& Miller, A.E. (1976). It's too late for ethics courses in business schools, Business and Society Review (Spring): 39-42.

Nonis, S., \& Swift, C.O. (2001). Personal value profiles and ethical business decisions. Journal of Education for Business, 70(5): 251-257.

Piper, Th.R., Gentile, M.S., \& Parks, S. D. (1993). Can ethics be taught? Boston, MA: Harvard Business School.

Rest, J. (1986). Moral development: Advances in research and theory. New York: Praeger Publishers.

Rest, J. \& Narváez, D. (eds.): (1994). Moral development in the professions, Hillsdale, NJ: Erlbaum. 
Pellegrino, E.D. (1978). Ethics and the moral center of the medieval enterprise, Bulletin of the New York Academy of Medievalism 54: 623-631.

Sherwood, J., \& Glidewell, J. (1971). Planned renegotiation: A norm OD intervention. Paper No. 228, Herman C. Krannert School of Industrial Administration, Purdue University, Lafayette, IN.

Sims, R.R. (2002). Business ethics teaching for effective learning, Teaching Business Ethics, 6(4): 393-410.

Sims, R.R. \& Sims, S.J. (1991). Increasing applied business ethics courses in business school curricula, Journal of Business Ethics 10: 211-219.

Stewart, K., Felicetti, L. \& S. Kuehn. (1996).The attitudes of business majors toward the teaching of business ethics, Journal of Business Ethics 15, 913-918.

Trevino, L.K., \& McCabe, D. (1994). Meta-learning about business ethics: Building honorable business school communities, Journal of Business Ethics 10: 211-219.

Trevino, L.K., \& Nelson, K.A. (1999). Managing business ethics $2^{\text {nd }}$ ed. New York: John Wiley $\&$ Sons.

Weber. J. \& Glyptis, S.M. (2000). Measuring the impact of a business ethics course and community service experience on students' values and opinions, Teaching Business Ethics 4: 341-358. 
